\title{
PERCEPÇÃO DE EDUCADORES \\ DO MUNICIIPIO DE MANAÍRA (PB) SOBRE A IMPORTÂNCIA DO DEBATE DA PROBLEMÁTICA DOS RESÍDUOS SÓLIDOS E O USO DA PRÁTICA DE ENCENAÇÃO TEATRAL COMO INSTRUMENTO DIDÁTICO PARA A EDUCAÇÃO AMBIENTAL NO ENSINO BÁSICO
}

\author{
José Vagner Delmiro Nogueira ${ }^{1}$ \\ Nércia Delmiro Nogueira ${ }^{2}$ \\ Cherliane Ferreira Carneiro Nogueira ${ }^{3}$
}

Resumo: O presente trabalho teve como objetivo ministrar uma palestra para fins de transmissão e enriquecimento de informações atuais; apoiada com 0 usa da prática da encenação teatral, para melhor discursão e reflexão geral. A pesquisa constou também de um levantamento discursivo de reflexão e abordagem geral. Como verificamos nos resultados a formação e capacitação dos educadores para trabalhar as questões ambientais em sala de aula, é uma necessidade real, onde o desenvolvimento de novas metodologias de ensino se configura como um instrumento fundamental neste desenvolvimento educacional e social promovidos pela a Educação Ambiental. Além de esta proporcionar o melhor desenvolvimento sustentável para toda a sociedade.

Palavras-chave: Educação; Meio Ambiente; Pedagogia.

\footnotetext{
${ }^{1}$ Universidade Federal Rural de Pernambuco. E-mail: wagneraporgeu@hotmail.com

${ }^{2}$ Instituto Federal de Educação, Ciência e Tecnologia da Paraiba. E-mail: nercyadna@hotmail.com

${ }^{3}$ Faculdade de Formação Teológica. E-mail: charly.ferreira@hotmail.com
} 


\section{Introdução}

As problemáticas provindas dos resíduos sólidos e das questões que afligem o meio ambiente são uma realidade em toda parte do planeta desde os países mais desenvolvidos até os menos desenvolvidos, pois efeitos negativos ao meio ambiente trazem consequências devastadoras para toda população mundial. A população Brasileira produz hoje, em média $1 \mathrm{~kg}$ de resíduo sólido por dia tendo como consequências a ineficiência da coleta e tratamento dos resíduos, provocando assim o seu acumulo em locais impróprios, e este corresponde a um dos fatores mais preocupante presenciados na atualidade. Tratando-se da região Nordeste $65 \%$ do lixo é destinado ao lixão e não tem tratamento adequado (BARBOSA, 2013).

Atualmente no Brasil a lei 12.305 de 02 de agosto de 2010 institui a Política Nacional de Resíduos Sólidos, onde a mesma estabelece diretrizes relativas à gestão integrada e ao gerenciamento de resíduos sólidos, bem como prever a extinção dos lixões nas cidades do país.

Dentre as principais preocupações mundiais estão o grande aumento populacional nos últimos anos; que tem como uma das consequências o grande acúmulo de resíduos sólidos gerados por esta população. Provocando assim elevados danos aos níveis de saúde da humanidade e graves dados ambientais ao solo, água e o ar (FADINI; FADINI, 2001).

Em se tratando de Manaíra (PB), a problemática dos resíduos sólidos "lixo" é uma realidade visível, pois a cidade apresenta uma ineficiência na gestão dos resíduos sólidos bem como a inexistência do pensamento e da incorporação do conceito de responsabilidade compartilhada pelos resíduos sólidos. Onde parte do lixo produzido pelos moradores é abandonado em terreno baldio ou lançado na lagoa central da cidade, fatos que levam ao aumento de focos de transmissão de doenças (BEZERRA, 2013).

A percepção ambiental corresponde a um importante instrumento de avaliação da consciência ambiental e da inter-relação do homem e seu meio ambiente. Trata-se de conhecer as percepções e reações expressas por cada individuo perante o seu meio ambiente, bem como os efeitos dessas em caráter individual e coletivo (FERNANDES, et al. 2003).

O estudo da percepção ambiental depara-se com valores e hábitos culturais inadequados, que provocam danos ao meio ambiente, muitas vezes irreparáveis. Neste contexto a análise da percepção ambiental corresponde a um importante instrumento na identificação das problemáticas ambientais promovidos por diferentes grupos sociais; possibilitando assim, melhores entendimentos e tomadas de decisões frente a estas problemáticas (SILVA, 2008).

A educação tem papel fundamental no processo de mudança de hábitos e atitudes culturais improprias para a atual situação da sociedade e em especial perante o Meio Ambiente. Sendo assim a Educação Ambiental como modalidade interdisciplinar e transversal tem importância primordial neste 
processo e traz novas formas educacionais, para o desenvolvimento de toda a sociedade. Como forma de melhor entendimento das teorias ambientais e cotidianas, o bom uso de instrumentos metodológicos práticas como: teatro, oficinas, palestras dentre outros artifícios da educomunicação, são ferramentas essenciais (FALCÃO, 1998).

\section{A Educação Ambiental no processo de ensino e construção da cidadania}

As contribuições que a Educação Ambiental pode proporcionar são infinitas, mas cabe destacarmos a sua atuação na participação social em elevar os níveis de cidadania e a proporcionar um desenvolvimento sustentável permanente, onde as ações devem estar focadas sobre as transformações das concepções dos indivíduos, para assim estes adquirirem a sua autonomia social e melhorar suas relações com o meio ambiente (TÓTH, 2012).

O conceito de meio ambiente em grande parte está voltado para a questão do meio natural, porém, este pode se voltar a definições mais amplas como o ambiente social, político, escolar, entre outros; e a Educação Ambiental como instrumento educacional importantíssimo, constrói satisfatoriamente diferenciações e especificações para tal conceito. Proporcionando assim o melhor entendimento deste e contribuindo na construção da cidadania e consciência ambiental do homem (ZULAUF, 2000).

A formação dos profissionais da educação é de extrema importância, para a melhor articulação dos componentes curriculares frente às realidades locais, pois só desta maneira é que a educação adquire uma postura cidadã e assim formará indivíduos capazes de refletir perante as suas próprias problemáticas. Para fins de melhor desenvolvimento do ensino- aprendizagem por parte dos educadores a boa articulação da teoria com a prática de ensino configura uma medida chave neste desenvolvimento (PRADA, et al., 2010).

\section{Prática de ensino em Educação Ambiental}

As diretrizes e parâmetros estabelecidos pelo Ministério da Educação (MEC) para a Educação Ambiental no Brasil; determina que o desenvolvimento desta, deve ser por meio de três modalidades básicas: projetos, disciplinas especiais e inserção da temática ambiental nas demais disciplinas.

Para Freire, et. al. (2006) a Educação Ambiental nas escolas é desenvolvida sob duas vertentes: a ecológico-preservacionista, que trata a Educação Ambiental apenas para a conservação da natureza, sem se preocupar com os fatores sociais atuantes; e a socioambiental, que traz a Educação Ambiental numa perspectiva mais ampla de conservação ambiental e mudança social.

O desenvolvimento prático da Educação Ambiental nas escolas deve ser construído de acorde com as reais necessidades e realidades aos quais os educandos estão inseridos, com usos de métodos pedagógicas eficazes 
capazes de desperta a consciência crítica construtiva dos mesmos (SILVA, et al., 2012).

A principal prática utilizada para o ensino da Educação Ambiental pela maioria dos educadores corresponde ao desenvolvimento do conteúdo teórico por meio do livro didático. Muito poucos fazem uso de brincadeiras, visitas de campo, exposição de imagens e vídeos e de dinâmicas e ludicidades: como a encenação teatral.

O uso da encenação teatral é uma porta que se abre na nova perspectiva do e ensino-aprendizagem, pois envolve essencialmente ações de entendimento diverso, faz uso da lógica do raciocínio e propõe novas possibilidades. Enfim, seus elementos ajudam no melhor entendimento das ações corriqueiras do dia-dia e no que pode vir a acontecer no futuro, ou seja, estimula a atenção e reflexão critica sobre assuntos importantes (CAVASSIN, 2008).

Tendo em vista a real situação advinda dos resíduos sólidos no município de Manaíra (PB), e preocupando-se com a melhor forma de transmitir as informações relevantes sobre as temáticas ambientais por parte dos educadores da rede de ensino do município, o presente trabalho teve como objetivo avaliar a percepção dos educadores da rede municipal e estadual de ensino de Manaíra, PB após a apresentação de uma palestra e de uma encenação teatral sobre o tema: A problemática socioambiental do lixo e a importância dos educadores na minimização desta problemática.

\section{Metodologia}

O estudo foi realizado no município de Manaíra - PB, localizada no sertão paraibano microrregião da Serra do Teixeira, onde a mesma apresenta uma população de 10.759 habitantes (IBGE, 2010). O estudo abrangeu 97 educadores, sendo 70 educadores da rede municipal de ensino e 27 educadores da Escola Normal Estadual Monsenhor Sebastião Rabêlo, durante o seu encontro pedagógico anual. Onde o mesmo fez uso de uma abordagem qualitativa, por meio da pesquisa descritiva participante; com resultados expressos de forma quantitativa e qualitativa (AGUIAR, 2010).

A pesquisa constou de uma apresentação em forma de palestra com discussões coletivas, sobre o tema: A problemática socioambiental do lixo e a importância dos educadores na minimização desta problemática, bem como uma encenação teatral sobre o tema abordado, e com uma avaliação final por meio de observação, conversação e da aplicação de um levantamento em forma de questionário contendo duas perguntas discursivas sobre a temática abordada.

A pesquisa é uma ferramenta primordial das ciências na investigação e avaliação da realidade e na previsão do que pode vir a acontecer, tornando assim uma atitude pratica teórica que sempre esta inacabada e permanente. (MINAYO, 2004).

Revbea, São Paulo, V. 10, Nº 1: 291-300, 2015. 


\section{Resultados e discussão}

A capacitação e a formação dos educadores em caráter continuo, é uma preocupação real de toda a rede de ensino visto as reais necessidades que os educadores necessitam para atualizarem seu nicho de informações e aperfeiçoamento de suas metodologias.

A temática apresentada na palestra abordou assuntos relevantes de âmbito global como a poluição do ar, da água e do solo e o grande problema do lixo nas localidades urbanas e rurais; o mesmo proporcionou a discursões entre os educadores, onde podemos observar a elevação do tema consumismo e desenvolvimento sustentável por parte dos educadores, que em um dos momentos da palestra cerca de quatro educadores comentaram o real conflito existente entre o sistema econômico vigente e as preocupações com os recursos naturais. A palestra trouxe também as principais alternativas para tentar minimizar a problemática do acumulo de lixo e excessivo uso de matérias por parte de educadores e funcionários da educação, onde se sugeriu o uso da tecnologia da informática para evitar o aumento de consumo de papel por todos que fazem parte da educação, e tentar seguir o principio dos 7rs (repensar, recusar, reduzir, recuperar, reutilizar, reciclar, reintegrar) e que estas atitudes sejam dizimadas para todos da comunidade local. Os educadores se mostraram estimulados a seguirem esta nova forma de trabalhar em busca da minimização dos efeitos negativos ao meio ambiente. Mostraram - se também motivados a cada vez mais a buscarem o seu aperfeiçoamento com relação a esta temática, em especial pelo fato desta ser de caráter interdisciplinar e transversal. (Figura 1)

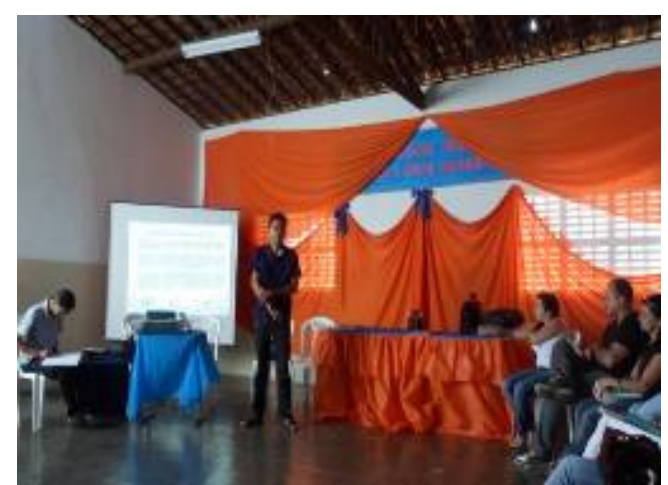

Figura1: Palestra Com educadores da Escola Normal estadual Monsenhor Sebastião Rabêlo. Fonte: Vagner Delmiro (2014)

Podemos observar também a grande preocupação dos educadores em se trabalhar a sensibilização das crianças na nova temática ambiental visto a pouca informação e conhecimento de seus pais, além de uma cultura que pode vir a destruir o conhecimento construído na escola. Podemos observar também que os educadores de as ambas as instituições em estudo demostraram a grande dificuldade de se trabalhar a prática dos conhecimentos teóricos ambientais, para tanto o teatro apresentado nos encontros pedagógicos trouxe a problematização dos resíduos sólidos, conhecido popularmente como lixo, que possui grande valor econômico, onde $95 \%$ destes 
podem ser reaproveitáveis e reciclado. Foi encenado a "historia de duas donas de casa: "Rita" que é uma mulher informada, que gosta de estar por dentro das novidades que rolam em sua cidade e no mundo. "Francisca" que é uma Dona de casa que adora cuidar de sua casa e dos seus filhos, inteligente e simpática. "João" é um rapaz bem sucedido, que trabalha na cooperativa recicla e adora o seu trabalho. "Fernanda" é uma estagiária da Consulplan consultoria que faz parte da elaboração do Plano Municipal de Gerenciamento Integrado de Resíduos Sólidos (PMGIRS) do município de Manaíra-PB, que dissemina informações sobre o PMGIRS" ( ALVES, 2014). (Figuras 2, 3, 4 e 5)
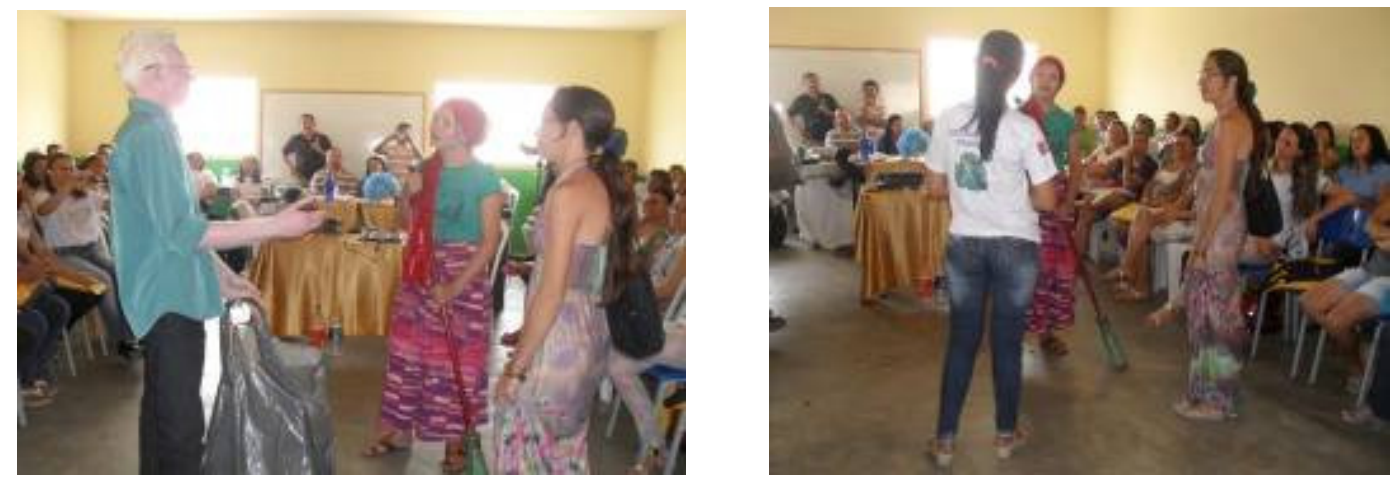

Figuras 2 e 3: Encenação teatral para educadores da rede municipal de ensino. Fonte: Vagner Delmiro(2014)
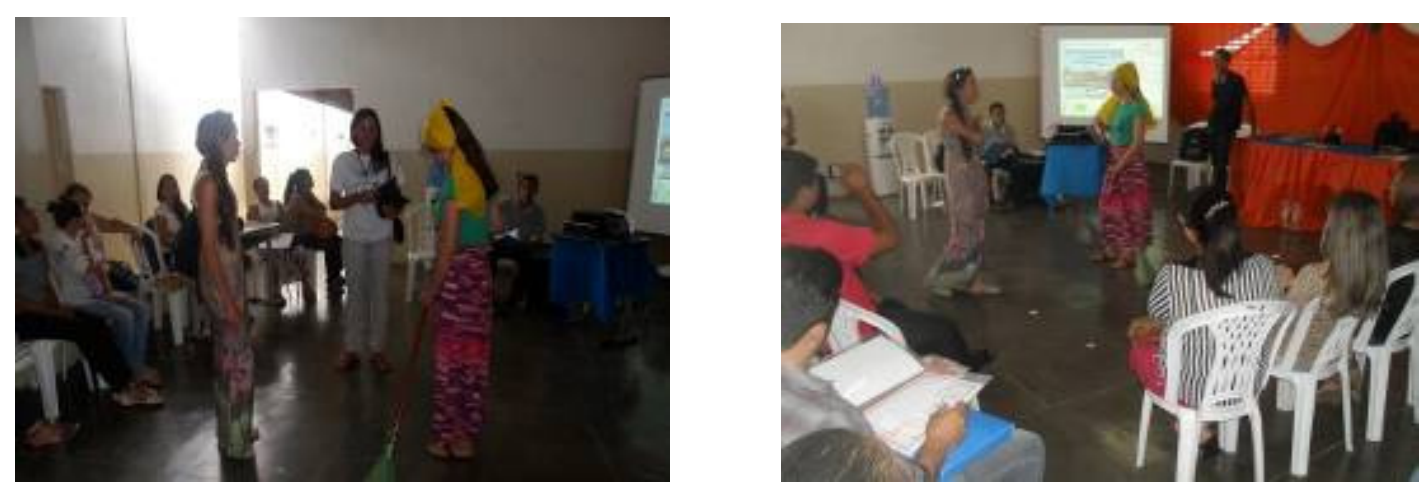
ERROR: stackunderflow OFFENDING COMMAND:

STACK : 